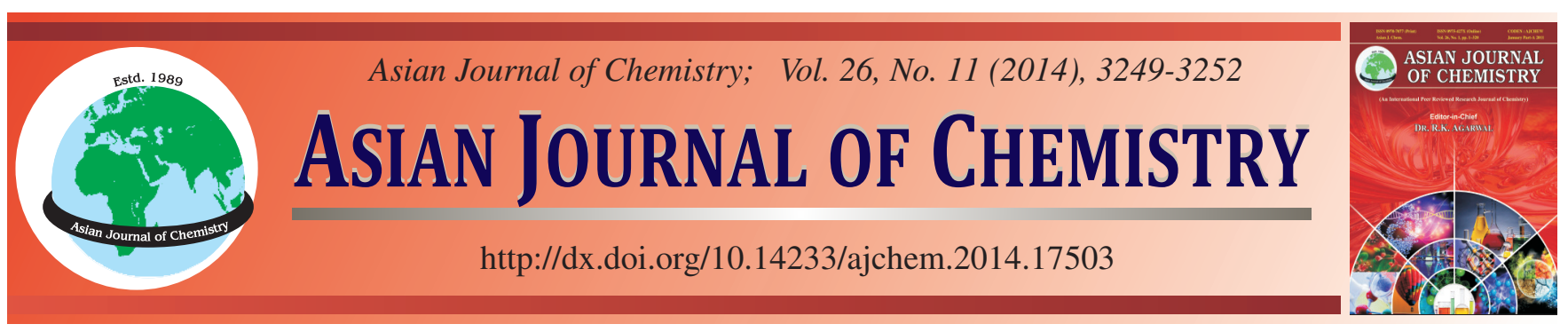

\title{
Membrane Fouling and Cleaning by Hybrid Membrane Bioreactor Treating Mustard Tuber Wastewater
}

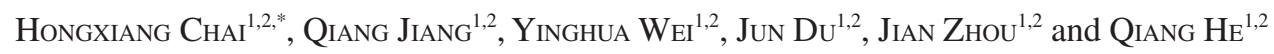

${ }^{1}$ Key Laboratory of the Three Gorges Reservoir Region's Eco-Environments, Ministry of Education Chongqing University, Chongqing 400045, P.R. China

${ }^{2}$ National Centre for International Research of Low-Carbon and Green Buildings, Chongqing University, Chongqing 400045, P.R. China

*Corresponding author: Tel/Fax: +86 23 65120980; E-mail: chaihx@cqu.edu.cn

Received: 3 February 2014;

Accepted: 31 March 2014;

Published online: 25 May 2014;

AJC-15225

\begin{abstract}
When treating a typical mustard wastewater by hybrid membrane bioreactor, membrane fouling was unavoidable. To investigate this problem, an experimental study was carried out to compare the performances of the aerobic membrane bioreactor and anoxic/aerobic membrane bioreactor. Membrane cleaning experiments were studied as well. The results showed that, the initial flux of the two bioreactor was 17.6 and $15.4 \mathrm{~L} / \mathrm{m}^{2} \mathrm{~h}$ and the final flux was 15.4 and $8.3 \mathrm{~L} / \mathrm{m}^{2} \mathrm{~h}$, respectively. In addition, their flux tended to be steady at 30 and 65 min, respectively. Therefore, the aerobic membrane bioreactor has a relative efficient operation. Soaking in $0.5 \%$ hydrochloric acid following $0.5 \%$ sodium hypochlorite could make the flux recovered with $82 \%$ and it was the mosteffective way of membrane cleaning.

Keywords: Mustard wastewater, Hybrid membrane bioreactor, Fouling, Cleaning.
\end{abstract}

\section{INTRODUCTION}

With the rapid development of the three Gorges Reservoir economy, the level of intensive producing of its pillar business mustard is getting higher; its scale is getting larger and larger with more and more producing enterprises. But organic wastewater with high concentration of salt and nitrogen from some pickle processing enterprises is discharged directly without effective treatment. As a result, the ecosystems of many rivers in the reservoir are facing a real danger and the life of local inhabitants is caused tremendous harmful.

As an efficient technology for municipal and industrial wastewater treatment, membrane bioreactors (MBRs) played an increasingly important role in the past decade ${ }^{1,2}$. But a major problem hindering the widespread application of membrane bioreactors for wastewater treatment is the rapid decline of the permeation flux with time as a result of membrane fouling ${ }^{3}$. Fouling results in degradation of membrane performance (such as permeate water flux and quality) and ultimately shortens membrane life ${ }^{4}$. Besides, membrane fouling decreases water production rate and increases complicacy of membrane filtration operations since the system has to be ceased frequently to restore the flux by back-flushing. Therefore, studying causes of membrane fouling and membrane cleaning are major challenges. The formation of membrane fouling is divided into two steps: (1) membrane flux decline at initial stage caused by concentration polarization; (2) long term membrane flux decline caused by particle deposition and solute adsorption. ${ }^{5}$ Many factors that might influence membrane fouling of MBRs have been reported, but the main factors are shown as following: (1) membrane materials ${ }^{6}$; (2) mixture characteristics ${ }^{7-9}$; (3) operating conditions ${ }^{10-12}$. Cleaning is one of the most pivotal steps for maintaining membrane performance, such as permeability and selectivity. In general, cleaning should be efficient, easy and fast, with no damage to the membrane and the installation and must satisfy sanitary requirements ${ }^{13}$. Membrane cleaning methods usually include physical, chemical, physicochemical and biological methods ${ }^{14-16}$. There are number of studies about membrane cleaning until now and the chemical methods proved to be the relative effective ways ${ }^{17-20}$. But it is a difficult and hot spot to seek the optimum combinations of chemical agents on different conditions.

The purpose of this study was to seek an economical and efficient system through the different membrane fouling level between aerobic membrane bioreactor and anoxic/aerobic membrane bioreactor. In addition, the cleaning methods had been studied and an efficient method was put forward when treating mustard wastewater. 


\section{EXPERIMENTAL}

Experiment set-up: (1) The schematic of the aerobic membrane bioreactor in this study is shown in Fig. 1(a). The effective volume of the reactor was $400 \mathrm{~L}$, with a size of 108 $\mathrm{cm} \times 75 \mathrm{~cm} \times 60 \mathrm{~cm}$ (length $\times$ width $\times$ height). The reactor was divided into biota zone and diaphragm zone. The biota zone was filled with semi-soft biofilm filler and the biofilm density was $30 \%$. The diaphragm zone was filled with hollow fiber membrane module. (2) The schematic diagram of the anoxic/aerobic membrane bioreactor in this study is shown in Fig. 1(b). The effective volume of the reactor was $650 \mathrm{~L}$, with a size of $100 \mathrm{~cm} \times 50 \mathrm{~cm} \times 138 \mathrm{~cm}$ (length $\times$ width $\times$ height). The reactor was divided into anoxic zone, aerobic zone and diaphragm zone. The anoxic zone was provided with mixing device and its size was $20 \mathrm{~cm} \times 50 \mathrm{~cm} \times 138 \mathrm{~cm}$ (length $\times$ width $\times$ height). The aerobic zone was filled with semi-soft biofilm filler and the biofilm density was $15 \%$, its size was 50 $\mathrm{cm} \times 50 \mathrm{~cm} \times 138 \mathrm{~cm}($ length $\times$ width $\times$ height $)$. The diaphragm zone was filled with hollow fiber membrane module.

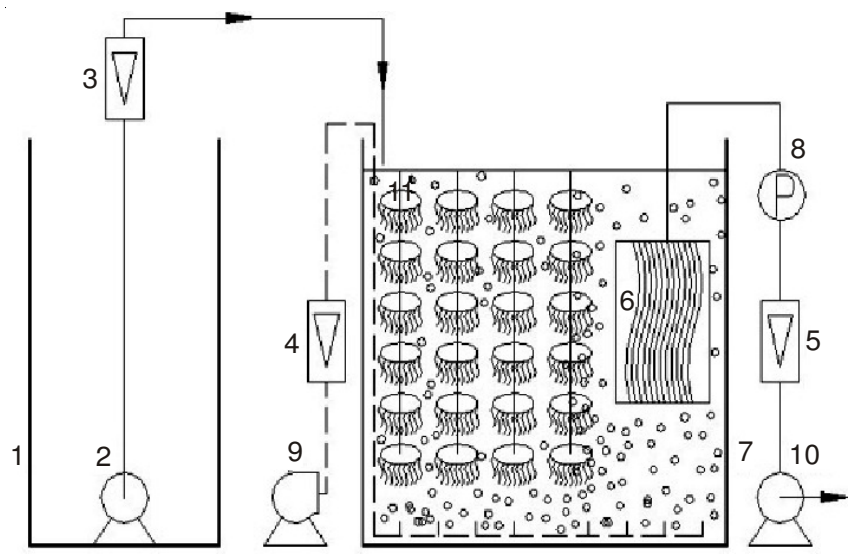

(a) Aerobic membrane bioreactor

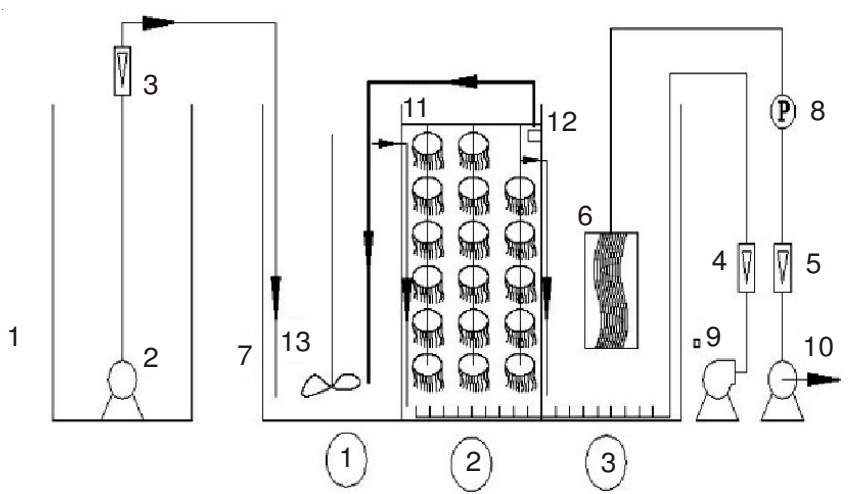

(b) Anoxic/aerobic membrane bioreactor

Fig. 1. Schematic diagram of the membrane bioreactors. 1-regulation tank 2-influent pump 3-5-flowmeter 6-membrane module 7-Mixed MBR 8-pressure gage 9-aerator pump 10-suction pump 11-biofilm filler 12-reflux pump 13-mixing pump. (1) anoxic zone (2) aerobic zone (3) diaphragm zone
The two reactors adopted continuous inflow of raw wastewater and intermittent discharge of effluent. In these two reactors, each membrane module was provided with a valve to control inflow. The suction pumps worked in intermittent operation mode and the suction/cease time was controlled by programmable logic controller (PLC) electric cabinet. The membrane flux was measured by flowmeter and transmembrane pressure was measured by negative pressure meter. The bottoms of the reactors were provided with perforated aerator pipe (the diameter was $20 \mathrm{~mm}$ ). In this experiment, the wastewater flow can form counter-clockwise circulation through controlling the aeration intensity of biota(aerobic) zone and diaphragm zone. The treated wastewater was extracted through collecting pipes at last.

Wastewater composition: The experimental wastewater used in this study was anaerobic tank effluent of the wastewater treatment plant provided by Fuling Mustard Tuber Group Co., Ltd, Chongqing, China. The quality of the influent is given in Table-1.

Analytical methods: Parameters were tested periodically and analyzed according to monitoring and analysis method of water and wastewater ${ }^{1}$ and the standard methods for the examination of water and wastewater which was published by American public Health Association².

Experimental procedure: The experiment was divided into two stages. The first stage was aimed at studying the different membrane fouling situations and the second stage was seeking the most efficient cleaning method. Four groups of experiments were designed to study on treating mustard wastewater by aerobic membrane bioreactor using PVDF membrane. On the condition of different feed loadings and normal temperature and on the condition that the bio-film density was $15 \%$, salinity was 2-3\% DO was 4-5 mg/L, HRT was $2.7 \mathrm{~h}$, suction pumps were operated for 10 minutes and closed for $3 \mathrm{~min}$ each time, TMP was $15 \mathrm{KPa}$, studied the membrane fouling levels. Four groups of experiments were designed to study on treating mustard wastewater by anoxic/ aerobic membrane bioreactor. On the condition of different feed loadings and normal temperature and on the condition that the bio-film density was $15 \%$, salinity was $2-3 \%$, DO was $1 \mathrm{mg} / \mathrm{L}$ and MLSS was $2000 \mathrm{mg} / \mathrm{L}$ in the anoxic zone, the bio-film density was $15 \%$, HRT was $2.7 \mathrm{~h}$, DO was $4-5 \mathrm{mg} / \mathrm{L}$ and MLSS was $6000 \mathrm{mg} / \mathrm{L}$ in the aerobic zone, the ratio of recycling the mixture was $200 \%$, suction pumps were operated for $10 \mathrm{~min}$ and closed for 3 min each time, TMP was $15 \mathrm{KPa}$, studied the membrane fouling levels.

\section{RESULTS AND DISCUSSION}

Different membrane fouling situations between aerobic membrane bioreactor and anoxic/aerobic membrane bioreactor: Fig. 2 shows the flux decline regularity when the two reactors operated with their own optimum operating feeding load. At the beginning, the membrane flux of aerobic

\begin{tabular}{|c|c|c|c|c|c|c|}
\hline \multicolumn{7}{|c|}{$\begin{array}{c}\text { TABLE-1 } \\
\text { QUALITY OF THE INFLUENT }\end{array}$} \\
\hline Parameter & $\begin{array}{l}\text { Salinity } \\
(\%)\end{array}$ & $\begin{array}{c}\mathrm{COD} \\
(\mathrm{mg} / \mathrm{L})\end{array}$ & $\begin{array}{c}\text { Ammonia } \\
\text { nitrogen }(\mathrm{mg} / \mathrm{L})\end{array}$ & $\begin{array}{l}\text { Total nitrogen } \\
(\mathrm{mg} / \mathrm{L})\end{array}$ & $\begin{array}{c}\text { Total phosphorus } \\
\text { (mg/L) }\end{array}$ & $\begin{array}{c}\text { Suspended solids } \\
(\mathrm{mg} / \mathrm{L})\end{array}$ \\
\hline Value & $2-3$ & $770-1240$ & $103-191$ & $207-409$ & $21-48$ & $237-525$ \\
\hline
\end{tabular}




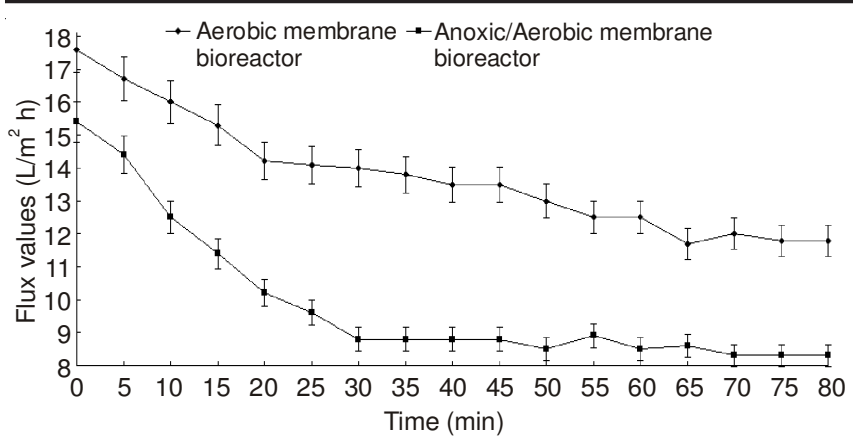

Fig. 2. Contrast on the decline of membrane fluxes

membrane bioreactor and anoxic/aerobic membrane bioreactor was 17.6 and $15.4 \mathrm{~L} / \mathrm{m}^{2} \mathrm{~h}$, respectively. However, the flux value was reduced to 11.8 and $8.3 \mathrm{~L} / \mathrm{m}^{2} \mathrm{~h}$, respectively at $80 \mathrm{~min}$. Analysis showed that the difference of the environment which the membrane of the two systems may be the main reason for the difference. In the aerobic membrane bioreactor, the concentration of suspended solids was $2000 \mathrm{mg} / \mathrm{L}$. However, the sludge concentration was $6000 \mathrm{mg} / \mathrm{L}$ in the anoxic/aerobic membrane bioreactor. So, its microbial quantity was far more than that in the anoxic/aerobic membrane bioreactor. Analysis showed that the extracellular polymeric substances (EPS) concentration increased with the sludge concentration and EPS was considered as the most significant factor membrane fouling ${ }^{1}$. Therefore, the fouling degree ofaerobic membrane bioreactor was lower than that of the anoxic/aerobic membrane bioreactor with the same operating time and the aerobic membrane bioreactor operated more effectively.

Chemical cleaning: The recovery rates after different chemical cleaning methods were shown in Table-2: (1) Soaking in hydrochloric acid aimed to remove the inorganic materials in the membrane pores. It can be found that the flux recovery rate was slightly higher than that of physical cleaning alone. But the physical cleaning contributed $20 \%$ of the recovery rate and the $\mathrm{HCl}$ contributed only $8 \%$. Studies identified that some metals such as Fe and Al could cause the irreversible membrane fouling and acid cleaning method had a significant effect on $\mathrm{it}^{24}$, nevertheless, the concentrations of such metals in mustard wastewater were quite low. As a result, only $8 \%$ removal rate was obtained by $\mathrm{HCl}$ cleaning; (2) soaking in sodium hypochlorite aimed to remove the organic foulants in the pores. The result showed that the $\mathrm{NaClO}$ exhibited an excellent performance for the fouled membrane and the flux could be greatly improved and it could be recovered to $73 \%$ of initial flux. Another similar study showed that, the permeability recovery was $64.5 \%$ using $0.05 \% \mathrm{NaClO}$ and $55.1 \%$ using $0.5 \% \mathrm{H}_{2} \mathrm{SO}_{4}$ after the same soak time ${ }^{25}$, it indicated that $\mathrm{NaClO}$ was more effective than acid in membrane cleaning. Analysis showed that the EPS could form a cake layer on membrane surface and $\mathrm{NaClO}$ could efficiently destroy the cake layer structure with it's oxidizing characteristic, besides, $\mathrm{NaClO}$ sometimes entered the pores and increased their effective diameter ${ }^{26-28}$; (3) after soaking in $\mathrm{HCl}$ and $\mathrm{NaClO}$, the flux could be recovered to $82 \%$ of the initial flux. In addition, most of the recovery attributed to $\mathrm{NaClO}$. An experimental result showed that the $>97 \%$ flux recovery was achieved by $0.5 \mathrm{wt} \% \mathrm{NaClO}$ solution on certain conditions ${ }^{29}$.

Fig. 3 showed the membrane states after different chemical ways: (1) after $\mathrm{HCl}$ solution cleaning, there existed Bacilluslike substances on the membrane surface. The pores were clogged with foulants and the average size of the pores was $0.087 \mu \mathrm{m}$ (Fig. 3a); (2) after $\mathrm{NaClO}$ solution cleaning, the amount of Bacillus-like substances decreased and the foulants in the pores reduced as well. Besides, the pore size was recovered well and the average size was $0.13 \mu \mathrm{m}$ (Fig. 3b); (3) after combined $\mathrm{HCl}+\mathrm{NaClO}$ cleaning, the membrane surface was relatively clean and the average pore size was $0.15 \mu \mathrm{m}$ (Fig. 3c). Therefore, an $\mathrm{HCl}+\mathrm{NaClO}$ method can solve the flux decline effectively. It can remove the foulants on the

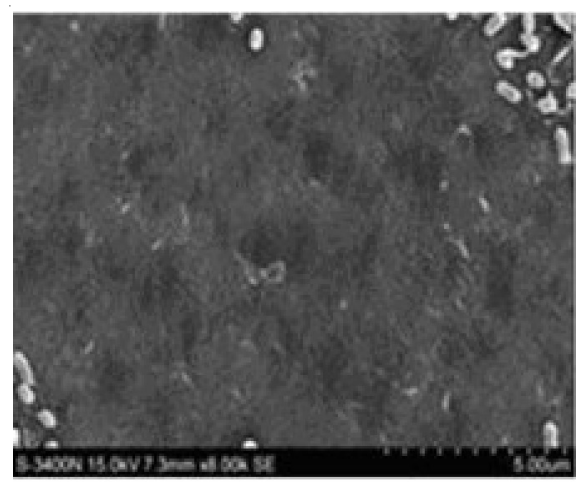

(a)

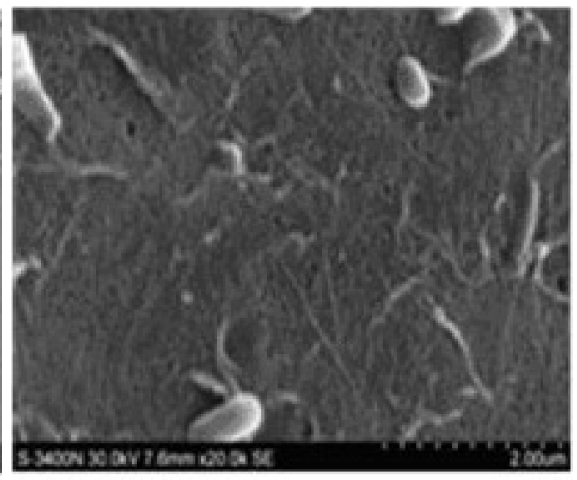

(b)

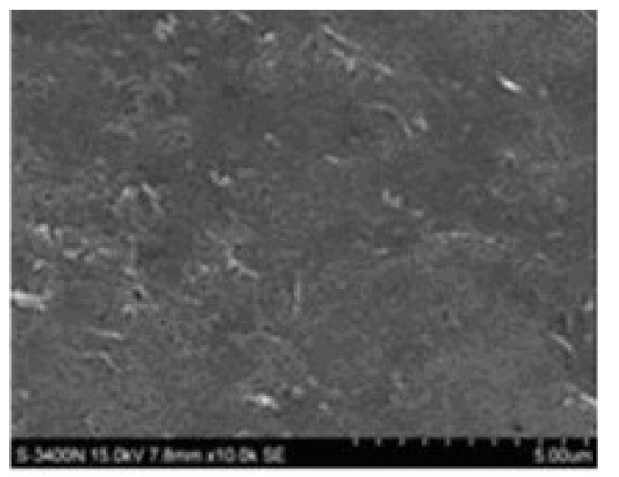

(c)

Fig. 3. SEM photograph after different chemsitry cleaning ways

TABLE-2

RECOVERY RATES AFTER DIFFERENT CHEMICAL CLEANING WAYS

\begin{tabular}{lcc}
\hline \multicolumn{1}{c}{ Item } & Flux $\left(\mathrm{L} / \mathrm{m}^{2} \cdot \mathrm{h}\right)$ & Recovery rate \\
\hline Initial flux & 30 & - \\
Flux before cleaning & 5 & - \\
Physical cleaning $+0.5 \mathrm{wt} \% \mathrm{HCl}$ & 8.4 & 28 \\
Physical cleaning $+0.5 \mathrm{wt} \% \mathrm{NaClO}$ & 21.9 & 73 \\
Physical cleaning $+0.5 \mathrm{wt} \% \mathrm{HCl}+0.5 \mathrm{wt} \% \mathrm{NaClO}$ & 24.6 & 82 \\
\hline
\end{tabular}


membrane surface and foulants in the pores as well and then prolong the membrane life.

\section{Conclusion}

When treating mustard wastewater, the aerobic membrane bioreactor can operate more effectively than the anoxic/aerobic membrane bioreactor. In order to defer the growth rate of membrane fouling and control the resistance accumulation, it is always necessary to carry out membrane cleaning. Combined use of $0.5 \% \mathrm{HCl}$ and $0.5 \% \mathrm{NaClO}$ was the most effective chemical way to remove membrane foulants.

\section{ACKNOWLEDGEMENTS}

This study was supported by the Fundamental Research Funds for the Central University (Project No. CDJZR12210023) and the 111 Project, No. B13041.

\section{REFERENCES}

1. M. Sarioglu, G. Insel, N. Artan and D. Orhon, J. Chem. Technol. Biotechnol., 86, 798 (2011).

2. T. Stephenson, S. Judd, B. Jefferson and K. Brindle, Membrane bioreactor for Wastewater Treatment, IWA Publishing, London (2000).

3. A.L. Lim and R. Bai, J. Membr. Sci., 216, 279 (2003).

4. Q. Li and M. Elimelech, Environ. Sci. Technol., 38, 4683 (2004).

5. L. Song, J. Membr. Sci., 139, 183 (1998).

6. I.-S. Chang, P. Le Clech, B. Jefferson and S. Judd, J. Environ. Eng., 128, 1018 (2002).

7. F.G. Meng, H. Zhang, F.L. Yang, S.T. Zhang, Y.S. Li and X.W. Zhang, Separ. Purif. Tech., 51, 95 (2006).
8. H. Hasar and C. Kinaci, Desalination, 170, 161 (2004).

9. H. Nagaoka, S. Ueda and A. Miya, Water Sci. Technol., 34, 165 (1996).

10. J.A. Howell, J. Membr. Sci., 107, 165 (1995).

11. I.-S. Chang and S.J. Judd, Process Biochem., 37, 915 (2002).

12. P. Gui, X. Huang, Y. Chen and Y. Qian, Desalination, 151, 185 (2003).

13. A. Makardij, X.D. Chen and M.M. Farid, Food Bioprod. Process., 77, 107 (1999).

14. G. Trägårdh, Desalination, 71, 325 (1989).

15. Y.J. Zhao, K.F. Wu, Z.J. Wang, L. Zhao and S.S. Li, J. Environ. Sci. (China), 12, 241 (2000).

16. D. Kuiper, C.A. Bom, J.L. Van Hezel and J. Verdouw, Desalination, 14, 163 (1974)

17. A. Sofia, W.J. Ng and S.L. Ong, Desalination, 160, 67 (2004).

18. E. Bouhabila, Sep. Purif. Technol., 22-23, 123 (2001).

19. E. Liu, G. Huan, Q. Du and P. Men, Mem. Sci. Technol., 23, 65 (2006).

20. J.K. Shim, I.K. Yoo and Y.M. Lee, Process Biochem., 38, 279 (2002).

21. Monitoring and Analysis Method of Water and Wastewater, China Environmental Science Press, Beijing, edn 4 (2002).

22. APHA, Standard Methods for the Examination of Water and Wastewater, American Public Health Association, Washington, edn 21 (2005).

23. Z. Wang, Z. Wu and S. Tang, Water Res., 43, 2504 (2009).

24. K. Kimura, Y. Hane, Y. Watanabe, G. Amy and N. Ohkuma, Water Res., 38, 3431 (2004).

25. W.J. Gong, W.Z. Li and H. Liang, J. Chem. Technol. Biotechnol., 85, 1334 (2010).

26. Y. Ye, P. Le Clech, V. Chen, A.G. Fane and B. Jefferson, Desalination, 175, 7 (2005)

27. Y. Zhang, J. Tian, H. Liang, J. Nan, Z. Chen and G. Li, J. Environ. Sci. (China), 23, 529 (2011).

28. T. Mohammadi, S.S. Madaeni and M.K. Moghadam, Desalination, 153, 155 (2003).

29. M. Bartlett, M.R. Bird and J.A. Howell, J. Membr. Sci., 105, 147 (1995). 